3 Authors affiliations:

4 $7 \quad$ Italy

8

9 producers.

\title{
Prebiotics in infant nutrition: a critical appraisal
}

\section{Lorenzo Morelli ${ }^{1, *}$, Vania Patrone ${ }^{1}$, Angelo Pietrobelli ${ }^{2,3}$}

${ }^{1}$ DiSTAS, Department for Sustainable Food Process, Facoltà di Scienze Agrarie, alimentari e ambientali, Università Cattolica del Sacro Cuore, Piacenza - Cremona, Italy

${ }^{2}$ Department of Surgical, Dentistry, Gynecology and Pediatrics, University of Verona - Verona,

${ }^{3}$ Pennington Biomedical Research Center, Baton Rouge, LA, USA.

*Author to whom correspondence should be addressed.

Abstract: Supplementation of infant formula with ingredients potentially able to manage, in a way positive for the host, the gut microbiota of infants, is nowadays widely used by infant food

The impact of this class of compounds, named prebiotics, on gut microbiota composition, was initially measured on the enrichment of Bifidobacterium and Lactobacillus spp., but the use of culture-independent analytical techniques has allowed to establish that a larger number of intestinal microorganisms are affected by the ingestion of prebiotics.

However, despite a relevant number of scientific publications, actually there is no consensus on the amount of prebiotics to be administered daily, the potentially different actions exerted by prebiotics which differ in biochemical structures, as well as the impact of different percentages of the same prebiotics when used in mixtures and/or combination. 
23 This paper is aimed to critically review the available data on the use of prebiotics in infant formula, 24 with special attention paid to identify a link between, the dosage used, the mixture composition and 25 the observed outcomes, keeping in mind the influences in nutrition quality and growth influence.

26

27 Keywords: Prebiotics; Infant Nutrition; Infant formula; Gut microbiota; Lactobacillus;

28 Bifidobacterium; Fructo-oligosaccharides; Galacto-oligosaccharides; Polidextrose; Acidic 29 oligosaccharides.
30

32

33

34

35

36

37

38

39

40

41

42

\section{Introduction}


The concept of prebiotic as a "nondigestible food ingredient that beneficially affects the host by selectively stimulating the growth and/or activity of one or a limited number of bacterial species already resident in the colon, and thus improves host health" dates back to 1995 [1]. Prebiotics are then considered a specific fuel that indigenous probiotic bacteria can utilize to grow. Most commonly known and characterized prebiotics are fructo-oligosaccharides (FOS), galactooligosaccharides (GOS), inulin, lactulose, and breast milk oligosaccharides [2]. FOS are able to cross the digestive lumen, undigested and unabsorbed, to reach the ascending colon unmodified, where they will be metabolized by the resident probiotic component of the microbiota. Overall, oligosaccharides have a long history of use as food ingredients able to provide health benefits.

On this scenario, however, from the initial 1995 definition, several attempts to modify and/or improve the prebiotic definition have been done. In 2003, Reid et al. [3] defined prebiotics "nondigestible substances that provide a beneficial physiological effect on the host by selectively stimulating the favorable growth or activity of a limited number of indigenous bacteria". In 2004, the definition of prebiotics was further modified "selectively fermented ingredients that allow specific changes, both in the composition and/or activity in the gastrointestinal microflora that confers benefits upon host well-being and health" [4]. In 2007 the Food and Agricultural Organization (FAO) of the United Nations organized a Technical Meeting to update the definition of prebiotics. The outcome of this meeting was the following definition: "a non-viable food component that confers a health benefit on the host associated with modulation of the microbiota" [5]. In 2010 Gibson et al. [6] defined the narrower category of "dietary prebiotics" as "a selectively fermented ingredient that results in specific changes in the composition and/or activity of the gastrointestinal microbiota, thus conferring benefit(s) upon host health”. In 2015, Bindels et al. [7] proposed that specificity requirements should be removed on the basis of reports showing that multiple taxa, rather than particular species, were enriched by prebiotics. This proposal led to another definition of a prebiotic as "a non-digestible compound that, through its metabolization by 
microorganisms in the gut, modulates the composition and/or activity of the gut microbiota, thus, conferring a beneficial physiological effect on the host". In 2017 Gibson et al. [8] defined prebiotic a substrate that is selectively utilized by host microorganisms conferring a health benefit. This definition expands the concept of prebiotics to possible applications to body sites other than the gastrointestinal tract, and diverse categories other than food, while the requirement for selective microbiota-mediated mechanisms was retained.

A common point of all definitions is that prebiotics differ from dietary fibers, which promote the growth of a wide variety of gut microorganisms, as they selectively serve as nutrients for beneficial microorganisms harbored by the host, including administered probiotic strains and indigenous (resident) microorganisms. Therefore a prebiotic should not be broadly metabolized but elicit a metabolism biased towards health-promoting microorganisms within the indigenous ecosystem. Due to the fact that the concept of prebiotics is not so clearly defined and remains a controversy, Table 1 summarized all the definitions in order to give the insights of definition and have the ambitious to derive at the end a unique and accepted definition.

Table 1. The concept of prebiotic over time

\begin{tabular}{|c|c|c|}
\hline Definition & Authors & Reference \\
\hline $\begin{array}{l}\text { A nondigestible food ingredient that beneficially affects } \\
\text { the host by selectively stimulating the growth and/or } \\
\text { activity of one or a limited number of bacterial species } \\
\text { already resident in the colon, and thus improves host } \\
\text { health }\end{array}$ & $\begin{array}{c}\text { Gibson \& Roberfroid, } \\
1995\end{array}$ & {$[1]$} \\
\hline $\begin{array}{l}\text { Nondigestible substances that provide a beneficial } \\
\text { physiological effect on the host by selectively } \\
\text { stimulating the favourable growth or activity of a limited } \\
\text { number of indigenous bacteria }\end{array}$ & Reid et al., 2003 & [3] \\
\hline $\begin{array}{l}\text { A selectively fermented ingredient that allows specific } \\
\text { changes, both in the composition and/or activity in the } \\
\text { gastrointestinal microflora that confers benefits upon } \\
\text { host wellbeing and health }\end{array}$ & Gibson et al., 2004 & {$[4]$} \\
\hline $\begin{array}{l}\text { A nonviable food component that confers a health } \\
\text { benefit on the host associated with modulation of the } \\
\text { microbiota }\end{array}$ & Pineiro et al., 2008 & {$[5]$} \\
\hline $\begin{array}{l}\text { A selectively fermented ingredient that results in } \\
\text { specific changes in the composition and/or activity of } \\
\text { the gastrointestinal microbiota, thus conferring benefit(s) }\end{array}$ & Gibson et al., 2010 & [6] \\
\hline
\end{tabular}


upon host health

A nondigestible compound that, through its

metabolization by microorganisms in the gut, modulates composition and/or activity of the gut microbiota, thus

Bindels et al., 2015

conferring a beneficial physiological effect on the host

A substrate that is selectively utilized by host

microorganisms conferring a health benefit

Gibson et al., 2017

[8]

As regards gut health and microbiota management, the other side of the coin are probiotics whose definition seems to have reached, after more than half century from its first usage [9], a consensus among the scientific community as " live microorganisms that, when administrated in adequate amounts, confer a health benefit on the host" to exert a wide range of effects [10]. The Panel confirmed that, although some mechanisms might be shared between strains belonging to the same species/genus, health effects are strain-specific and claims of specific benefits must be determined at the strain level. Moreover, to exert the desired effect, any probiotic must be delivered at a functional dose, and the Panel stressed that to establish a clear association between any substance, including probiotics, and a desired effect it is important to examine dose response, among other criteria. It is thus interesting to note that, while probiotics are well described in term of adequate amount and specific role/effect as well as type of microorganisms, the definitions of prebiotics proposed to date have not considered either the specificity of the chemical composition of the prebiotic or its dosage. This is reflected by the heterogeneity of the studies available on prebiotics which differ a lot in terms of amount/dose and type of prebiotics administrated, making direct comparison among results very difficult and not really focused also in meta-analysis and systematic reviews [11].

Because there are on the market a wide range of prebiotics, the aim of this paper is to offer a critical appraisal of the existing literature about the clinical outcomes of these gut-directed ingredients in the age 0-12 months, when they are used as a supplement to formula milk.

\section{Methods}


Only randomized controlled trials (RCT) were eligible for inclusion. Enrolled subjects have to be aged 0-12 months; studies on preterm and unhealthy subject were included. Only full paper written in English were retained for analysis.

Studies in which prebiotics were not administered as an ingredient of formula, for example in capsules, were discarded. Studies in which synthetic human milk oligosaccharides were used were excluded.

A number of RCTs described the same study population but focused on different outcome measures; they were considered as separate reports and treated individually.

A search with the keywords "infants" and prebiotic(s)" and "formula" filtered for "clinical trials" in the databases PubMed, Scopus, Web Of Science, retrieved 145 items, after filtering for duplications, papers not in English, letters or not full papers..

Among them a further selection of 71 was done, discarding those dealing with probiotics synbiotics, those enrolling subjects older than 12 months of age, subjects in severe pathological conditions, or those out of scope of this paper (18) for specific reasons (see Supplementary Table.1)

\section{Results}

3.1. Studies assessing the effects of a single prebiotic ingredient

Table S2 is devoted to the outcomes obtained when a single probiotic ingredient has been tested in human trials.

Results obtained when GOS are used as only prebiotic ingredient, at the dosage of $0.4 \mathrm{~g} / 100$ $\mathrm{mL}[12-14]$ suggested that that at this dosage this prebiotic could have an impact on the microbiota composition; fecal parameters such stool consistency and volume are also positively affected, while GOS-supplemented formulas do not seem to exert any effect on the frequency of defecation.

Parameters related to health, such as the incidence of infections or allergic manifestations $[14,15]$, 
are not influenced by GOS supplementation, even when a slightly higher dose $(0.5 \mathrm{~g} / 100 \mathrm{~mL})$ is used [15].

GOS dosed at $0.8 \mathrm{~g} / 100 \mathrm{~mL}$ in the very first weeks of life seem to cause watery stools [13] and this observation could be used as starting point to establish a safety upper level of supplementation; this note is also supported by data provided in 2014 by Williams et al. [13]. These authors, in a trial conducted in United States in 2007-2008 with a formula supplemented with 0.8 $\mathrm{g} / 100 \mathrm{~mL}$ of GOS, reported a higher percentage of very soft stools in treated infants. Positive results additional to alteration of microbiota and stool composition are reported by Giovannini et al. [12] as they recorded a lower incidence of colic in the supplemented group of infants with respect to the control group.

Additionally, Paganini et al. [16] found a lower abundance of virulence and toxin genes in GOS-treated group when compared with the control and Fe only groups. Underwood et al. [17], on the other hand, did not detect significant increases in bifidobacteria compared with baseline in preterm infants dosed with GOS.

Turning to fructan prebiotics, among the 5 papers which reported the use of FOS as single prebiotic ingredient [18-22], only Kapiki et al. [20] showed significant, consistent effects on microbiota, in particular on the abundance of bifidobacteria, using $0.4 \mathrm{~g} / 100 \mathrm{~mL}$; a dose of 0.3 $\mathrm{g} / 100 \mathrm{~mL}[18,20,21]$, is most likely enough for FOS to have a positive influence on stool characteristics.

The use of kestose, a fructo-oligosaccharide, has been reported by Shibata et al. [23] to have a positive influence on SCORAD scores of atopic infants. Two papers [24,25] reported the use of fructans derived from agave (Agave tequilana Weber cv. Azul). After a safety assessment in healthy, full-term babies [24] two ingredients were assessed for impact on immune response, serum ferritin, C-reactive protein, bone metabolism, and gut bacteria changes. Analysis were performed at 20 - 27 days, and three months of age. The authors state that there were statistically significant 
155 differences for the groups of infants fed only with infant formula and with formula enriched with these fructans.

As far as inulin is concerned, Kim et al. [26] assessed the effects of native inulin in formulafed babies on gut microbiota, $\mathrm{pH}$, consistency and amount of feces, and on frequency of defecation at a daily dosage of about $5 \mathrm{~g} / \mathrm{d}$. The consumption of inulin increased significantly the content of Bifidobacterium in the feces of formula-fed babies compared to control, but neither the frequency of defecation nor stool consistency were affected by the consumption of inulin.

In the study by Closa-Monasterolo et al. [27], oligofructose-enriched inulin at a dose of 0.8 $\mathrm{g} / 100 \mathrm{~mL}$ was tested, and the authors found a tendency towards higher Bifidobacterium cell counts, with a significant higher frequency of depositions and a softer consistency of stools [28].

\subsection{Studies assessing the effects of combinations of prebiotic ingredient: not strictly gut-related} clinical outcomes of GOS/FOS administration

A group of papers, all of them with a very similar clinical design and a dosage of GOS/FOS of $0.8 \mathrm{~g} / 100 \mathrm{~mL}$, was devoted to establish a link between the use of this ingredient and immune response (Table S3). Moro et al. [29] reported that 102 infants in the prebiotic group and 104 infants in the placebo group (all of them at risk for atopy) completed the study (duration: 6 months). Ten infants in the intervention group and 24 infants in the control group developed atopic dermatitis. Prebiotic supplementation was also producing a significantly higher number of fecal bifidobacteria compared with placebo (maltodextrin) group. An hydrolyzed protein formula was used in both groups.

The same design has been used by van Hoffen et al. [30] to assess the effect of GOS/FOS on the immune response in infants at risk for allergy. An hypoallergenic whey formula with either 0.8 $\mathrm{g} / 100 \mathrm{~mL}$ or $0.8 \mathrm{~g} / 100 \mathrm{~mL}$ maltodextrin (placebo) were used for 6 months. At 6 months of age, plasma samples were collected from the 41 treated infants and the 43 subjects of the placebo group. 
180 GOS/FOS supplementation resulted into a significant reduction of total IgE, IgG1, IgG2 and IgG3, 181 but not of IgG4 amount. The authors concluded that GOS/FOS supplementation could be a method 182 to limit the atopic development.

An additional study on the effect of supplementation of GOS/FOS on plasma markers of allergic disease in infants at risk for allergy was published by Schouten et al. [31]; also in this study hypoallergenic whey formula containing $0.8 \mathrm{~g} / \mathrm{mL}$ of the GOS/FOS mixture was administered for 6 months to 34 infants, while the control group $(n=40)$ received maltodextrin; all of them at risk for atopy. In this paper immunoglobulin free light-chain (Ig-fLC) was checked as a marker of allergic disease. Results supported a positive role of GOS/FOS as in infants receiving the prebiotic mixture, the Ig-fLC levels were significantly lower compared to the placebo-fed infants.

MacDonald et al. [32] by means of an 8-week open-label, single-arm, pilot intervention study in 9 infants (8-week median age) tried to establish a role for prebiotics (GOS/FOS $0.8 \mathrm{~g} / 100 \mathrm{~mL}$ ) added to a protein substitute suitable for infants with Phenylketonuria. All infants exhibited microbiota dominated by bifidobacteria, although no statistically significant change from baseline was observed at study endpoint.

Arslanoglu et al. [33] showed a preventive effect of the prebiotic mixture GOS/FOS against infections during the first 6 months of life. In this study the cumulative incidence of all types of recurring infections was significantly lower in the GOS/FOS group; prebiotic mixture was used as an ingredient of a hypoallergenic formula. The dose used was $0.8 \mathrm{~g} / 100 \mathrm{~mL}$.

Bisceglia et al.[34] published a paper aimed to investigate the effect of dietary supplementation with prebiotics on moderate hyperbilirubinaemia in healthy, term infants. Seventysix consecutive newborns were randomly assigned to receive a formula containing $0.8 \mathrm{~g} / 100 \mathrm{~mL}$ GOS/FOS supplement or maltodextrins as placebo for 28 days. Bilirubin levels and daily defecation frequency was also recorded. A statistically significant lower transcutaneous bilirubin was detected 
204 in neonates receiving prebiotics, from $72 \mathrm{~h}$ of life, till the end of the dietary intervention (day 28).

205 Treated infants also showed a higher frequency of defecation, when compared to neonates on 206 placebo, over all the duration of dietary intervention.

The dose of $0.4 \mathrm{~g} / 100 \mathrm{~mL}$ has been used by Bruzzese et al. [35] in order to reduce the 208 incidence of intestinal and respiratory infections in healthy infants. In this massive study 352 209 subjects were enrolled and fed with the prebiotic formula or the control one for a period of one year. 210 The incidence of gastroenteritis and the number of children with multiple antibiotic courses/year 211 was lower in the supplemented group than in the controls.

A few other studies tested the effects of mixtures of GOS/FOS with atypical dosages, i. e. different from the concentrations $0.4-0.8 \mathrm{~g} / 100 \mathrm{~mL}$ (Table S4).

Brunser et al. [36] evaluated the effects on intestinal microbiota composition of infants but after an amoxicillin treatment for upper respiratory tract infections. This study is of particular relevance for the purpose of this review, in fact the mixture used was oligofructose and inulin in 70/30 proportion by weight (and not 9:1), at a dosage of $0.45 \mathrm{~g} / 100 \mathrm{~mL}$ after formula reconstitution. This dosage showed that infants fed a milk formula supplemented with prebiotics had higher counts of bifidobacteria and lactobacilli than those fed the same formula but without the prebiotics The total fecal bacterial count population returned to the levels before amoxicillin administration without differences between the groups, confirming that prebiotics do not influence the recovery of the total flora.

A dose different from the 0.4-0.8 g/100 mL was also used by Alliet et al. [37]: these authors used GOS/FOS in a 9:1 ratio but a dose of $0.6 \mathrm{~g} / 100 \mathrm{~mL}$. Aim of this study was the evaluation of prebiotics consumption related to cholesterol and triacylglycerol levels in infants. The study was organized into 3 arms: breast fed, standard formula and the same formula supplemented with GOS/FOS. Among the 187 infants which completed the study the total cholesterol and LDL levels 
were significantly lower in the formula-fed groups than in the breast-fed infants but there were no significant differences between the formula-fed groups. Authors concluded that there are no differences in total cholesterol and LDL cholesterol in infants receiving an infant formula with GOS/lcFOS (with this dosage) from infants receiving a control infant formula.

\subsection{Studies assessing the effects of combinations of prebiotic ingredient: intestinal effects of} GOS/FOS

The majority of papers reporting the use of GOS/FOS in a 9:1 ratio, were aimed to assess the impact of this prebiotic mixture on microbiota composition of full term infants, with special emphasis on lactobacilli, bifidobacteria, enterobacteriaceae and clostridia as well as on defecation frequency and stool parameters (Table S5).

Moro et al., in two different clinical trials [38,39] used two levels of prebiotics $(0.4$ and 0.8 $\mathrm{g} / 100 \mathrm{~mL}$ ) to supplement infant formula in 180 infants in order to identify the most active dose in promoting a microbiota composition close to that one on breast fed babies. After these preliminary steps, and since the paper of Knol et al. [40], the selected dosage seemed to be the $0.8 \mathrm{~g} / 100 \mathrm{~mL}$.and used in the majority of papers. Knol et al. [40] analysed by means of plate counts and fluorescent in vivo hybridization (FISH) the stools of 19 infants treated with the GOS/FOS mixture in comparison with 19 infants fed breast milk and 15 fed the control formula. In addition to bacterial counts several stool parameters were assessed such as lactate, short-chain fatty acids (acetate, propionate), $\mathrm{pH}$, stool consistency. All of them were more close to parameters detected in breast-fed babies mainly when the $0.8 \mathrm{~g} / 100 \mathrm{~mL}$ was used. An increase in frequency of defecation was noticed by Moro et al. [38] only in infants receiving the $0.8 \mathrm{~g} / 100 \mathrm{~mL}$ dose.

Haarman \& Knol in two following papers used a quantitative PCR approach to evaluate species-specific changes in Bifidobacterium [41] and Lactobacillus [42] in full-term babied fed with 
252 a formula containing $0.8 \mathrm{~g} / 100 \mathrm{~mL}$ of the GOS/FOS mixture. In both articles this analytical

253 approach showed that the prebiotic mixture supports species that are dominant in breast-fed babies.

Bakker-Zierikzee et al. [43] compared the effects of GOS/FOS $0.8 \mathrm{~g} / 100 \mathrm{~mL}$ in 19 infants to

255 the impact of the use of a probiotic Bifidobacterium in the early stage of life (5 to 16 weeks). The 256 only significant difference was higher fecal acetate ratio and lactate concentration and a lower $\mathrm{pH}$ at 25716 weeks.

258 Costalos et al. [44],using a dose of dose of $0.4 \mathrm{~g} / 100 \mathrm{~mL}$, found a significantly higher stool 259 frequency and softer consistency in the prebiotic group while these outcomes were noticed only in 260 the group treated with $0.8 \mathrm{~g} / \mathrm{mL}$ in the paper by Moro et al. [38]. On the other hand, this paper [44] 261 confirms that, at this dosage, no statistically significant differences are detectable in the bacterial 262 counts. In addition, Holscher et al. [45] also using the low dose of $0.4 \mathrm{~g} / 100 \mathrm{~mL}$ reported that feces 263 from infants fed with prebiotics had a higher absolute number and proportion of bifidobacteria 264 when compared to control formula and they did not differ from breast-fed infants. 272 breast-fed group.

On the contrary, Vivatvakin et al. [46] using the low dosage reported better scores of gastrointestinal comfort in infants fed a whey-predominant formula containing long chain polyunsaturated fatty acids and GOS/FOS, when compared to infants fed a control caseinpredominant formula without additional ingredients. Healthy, full-term infants were randomized to receive exclusively either experimental $(n=67)$ or control formula $(n=69)$ from 30 days to 4 months of age; exclusively breast-fed infants $(n=67)$ served as reference. Compared to the control, the experimental group had less hard stools as well as a microbiota composition closer to that of the 
278 slightly harder than those of breast-fed infants but the control group (formula without prebiotics)

279 had significantly harder stools at weeks 2 and 4. The total number of fecal bacteria increased in all 280 of the prebiotic groups. In the groups supplemented with $8 \mathrm{~g} / 100 \mathrm{~mL}$, Bifidobacterium counts were 281 significantly higher and were comparable with the breast-fed group.

Salvini et al. [48] recruited 20 newborns of hepatitis C virus-infected mothers who decided not to breast-feed. These neonates were randomly assigned to either a formula with $0.8 \mathrm{~g} / 100 \mathrm{~mL}$ of a GOS/FOS or a placebo formula (maltodextrin). Measured outcomes were anthropometric data, microbiological analysis of fecal samples, and blood leukocyte population. Prebiotic supplementation resulted in more fecal bifidobacteria and lactobacilli compared with the placebo group. These differences between the groups were maintained during the second half of the first year without any prebiotic supplementation, supporting a long lasting effect of the prebiotic treatment.

Holscher et al. [45] enrolled full-term, formula-fed (FF) infants compared to a breast-fed group $(\mathrm{BF})$. FF infants were randomized to consume a partially hydrolyzed whey formula with or without $0.4 \mathrm{~g} / 100 \mathrm{~mL}$ GOS/FOS. Fecal bacteria, pH, and SCFA were assessed at baseline, 3 weeks, and 6 weeks. Feces from infants fed prebiotics had a higher absolute number and proportion of bifidobacteria which did not differ from that of BF infants. Notably, the established bifidogenic formula milk fermented with Bifidobacterium breve and Streptococcus thermophilus [53,54]. Huet 
and GOS/FOS in healthy term infants enrolled before 28 days of age and followed up to 17 weeks of age. Four hundred and thirty infants were divided into 4 groups: (1) formula with scGOS/lcFOS, (2) formula + GOS/FOS $+15 \%$ fermented formula, (3) formula + GOS/FOS $+50 \%$ fermented formula, (4) formula $+50 \%$ fermented formula, in order to check the daily weight gain during intervention and to monitor infants' anthropometrics data, formula intake, number, and safety. Physiological and bacterial data were obtained from stool samples collected at baseline and at the end of the trial. Results showed equivalence of weight gain while no differences were observed in other controlled parameters. Supplementation with GOS/FOS provided beneficial effects such as a lower $\mathrm{pH}$, lower Clostridium difficile levels, and higher secretory immunoglobulin A levels. Vandeplas et al. [54] using the same sample size than above assessed the impact of this combination among formula, fermented formula and prebiotic on colic. After 4 weeks of treatment the research group demonstrated a reduced overall incidence of infantile colic in group 3 GOS/FOS $+50 \%$ FERM, better than in group 1 and 4 , suggesting a dose response for the fermented formula. The mixture GOS/FOS 9:1 has been also used also in feeding of preterm infants (Table S6).

Boehm et al. [55] used a dosage (i.e. $1 \mathrm{~g} / 100 \mathrm{~mL}$ ) higher than those used in full term infants ( 0.4 or $0.8 \mathrm{~g} 100 / \mathrm{mL})$; not surprisingly, they demonstrated a strong bifidogenic effect of prebioticsupplemented formula as well as a positive impact on stool frequency.

Mihatsch, et al. [56] used the same dosage to evaluate tolerability and the capacity of prebiotics to reduce stool viscosity and accelerate gastrointestinal transport, in order to improve feeding tolerance. Both these parameters were positively affected by the prebiotic supplementation in the 10 treated infants compared to the same number of control subjects.

Indrio et al. [52] measured gastric electrical activity and the gastric emptying time in 10 preterm neonates fed with a formula containing $0.8 \mathrm{mg} / 100 \mathrm{~mL} \mathrm{GOS} / \mathrm{FOS}$. After a feeding period of 15 days, both parameters were significantly improved when compared to the 10 infants of the placebo group. These results were confirmed in a larger study of the same research group [51] 
329 involving 49 preterm newborns. After an intervention period of 30 days, infants administered 0.8 $330 \mathrm{mg} / 100 \mathrm{~mL}$ GOS/FOS showed a percentage of EGG slow wave propagation and a gastric half 331 emptying time similar to those of breast-fed infants.

332 Modi et al. [57] performed a large study in preterm infants (79 control and 71 useful for the primary 333 outcome) using formula plus prebiotics to augment insufficient maternal milk volume; the prebiotic 334 milk was dosed at $0.8 / 100 \mathrm{~mL}$. The primary outcome was set in a total milk intake of $150 \mathrm{~mL} / \mathrm{kg} / \mathrm{d}$; 335 no significant differences were found in this outcome from trial entry to 28 days, while some 336 benefits were recorded for secondary outcomes.

Armanian et al. [58] evaluated if prebiotics have benefits for the management of hyperbilirubinemia in preterm neonates. The prebiotic group displayed lower bilirubin level and peak bilirubin level than the placebo group over the study period. In addition, stool frequency was significantly increased in the prebiotic group.

\subsection{Studies assessing the effects of combinations of prebiotic ingredients: effects of prebiotic} mixtures based on polydextrose (PDX)

Considerable research has been devoted to investigate the potential effects of polydextrose (PDX) in association with galacto-oligosaccharides (Table S7). published in 2007 by Ziegler and coworkers [59]. The study evaluated 2 different combinations of prebiotic ingredients, PDX, GOS and lactulose (LOS), at 2 different intake levels on growth and tolerance in healthy term infants up to 120 days of age. Dosage was $0.4 \mathrm{~g} / 100 \mathrm{~mL}$ (PG4) of a prebiotic blend containing PDX and GOS in a 50:50 ratio (74 subjects) or 0.8 g/100 mL (PG8) of a prebiotic blend containing PDX, GOS, and LOS, 50:33:17 ratio (76 subjects); a control group (76 subjects) fed with the same formula without any prebiotic supplementation was also enrolled. The authors reported that: "There were no statistically significant differences among the 3 formula 
353 groups for weight growth rate or length growth rate at any time point. Significant differences in 354 stool consistency were detected among the 3 formula groups at 30, 60, and 90 days of age with the 355 supplemented formula groups having looser stools than the control group. A statistical difference 356 was detected among the formula groups in 3 categories of adverse events: diarrhea (control vs 357 PG4,), eczema (PG4 vs control; PG4 vs PGL8), and irritability (control vs PGL8)".

Nakamura et al. [60] using the same trial design with the addition of a breast-fed reference group and focusing on the bacterial composition of gut microbiota, reported the lack of adverse effects in treated infants, and a stool consistency significantly softer or looser in the breast fed group than in all of the groups that received formula. As regards the bacterial communities they noticed that individual profiles tended to cluster by subject rather than by group.

The following five papers all used the PDX/GOS dose of $0.4 \mathrm{~g} / 100 \mathrm{~mL}$ in a $1: 1$ ratio of PDX/GOS.

Scalabrin et al.[61], in a study in which 230 infants completed the protocol, showed that consuming PDX/GOS resulted in softer stools than control at all times . Using qPCR, bacterial counts in PDX/GOS were closer to those of the breast-fed group.

Ashley et al.[62] published a paper in which the PDX/GOS mixture was compared to the same amount $(0.4 \mathrm{~g} / 100 \mathrm{~mL})$ of GOS only. The noticed softer stools for infants in the PDX/GOS and GOS groups versus control till 90 days but this positive remark remained 120 days for the PDX/GOS group only.

Hicks et al. [63] investigated the effect of PDX/GOS supplementation on calcium absorption in infants fed a formula containing or not prebiotics and in comparison with a group of human milk-fed (HM) infants. The authors did not observe any significant effect of prebiotics on calcium absorption or other markers of bone mineral metabolism. 
Pärtty et al. [64] used the PDX/GOS supplementation in preterm infants in comparison with the supplementation of a probiotic Lactobacillus. Both supplementation lasted for the first 2 months of life while infants were followed up for 1 year. The major result reported was that infants classified as excessive criers were significantly less in the prebiotic and the probiotic groups (no significant differences between the two treatments) than in the placebo group.

Finally, Luoto et al. [65] also using a cohort of preterm infants and the same prebiotic/probiotic comparison, hypothesized that early prebiotic or probiotic supplementation could reduce the risk of virus-associated respiratory tract infections (RTIs) during the first year of life. A significantly lower incidence of RTIs, including those due to rhinovirus, was detected in infants receiving prebiotics compared with those receiving placebo.

\subsection{Studies assessing the effects of combinations of prebiotic ingredients: effects of GOS/FOS in} association with pectin hydrolysate-derived acidic oligosaccharides (pAOS) The addition to formula of with $0.2 \mathrm{~g} / 100 \mathrm{~mL}$ acidic oligosaccharides (pAOS), derived from citrus pectin by enzymatic hydrolysis, was studied for the first time by Fanaro et al. [66] (Table S8). Three groups were enrolled: a placebo group (maltodextrins, 16 subiects), a pAOS group (16 subjects) and a reference group (15 subjects) with pAOS supplementation together with 0.6 $\mathrm{g} / 100 \mathrm{~mL}$ GOS/FOS $9: 1$. The only positive outcome detected in the pAOS treated infants was a stool consistency significantly softer in comparison with the group fed the standard formula. In infants fed the three oligosaccharides, bifidobacteria and lactobacilli counts were increased, the stool frequency was significantly higher while stool consistency scores were the lowest of the 3 groups.

Also Magne et al. [67] used the $0.6 \mathrm{~g} / 100 \mathrm{~mL}$ dose of GOS/FOS; these authors checked the impact of the 3 oligo-containing prebiotics on microbiota composition and also in this case, while the presence of GOS/FOS positively altered gut microbiota composition, the further addition of pAOS does not seem to have any effects. 
A further evaluation of this 3 faceted prebiotic supplementation has been published in 2001 by Piemontese et al. [68]; in this work, also aimed to established safety and gut impact of this new prebiotic formulation, the dose of $0.8 \mathrm{~g} / 100 \mathrm{~mL}$ of GOS/FOS was used. Growth, tolerance and adverse events were assessed at 8, 16, 24 and 52 weeks of age in three groups of infants. The prebiotic and control groups showed similar anthropometric parameters at each study point. The stool consistency in the prebiotic group was softer than in the control group at 8,16 and 24 weeks and closer to that of the breast-feeding group. There was no difference in the incidence of adverse events between the two formula groups.

After these preliminary papers a full range of studies (6 out of the total 15 selected for our analysis) has been published on the potential use of this 3 components prebiotic formula in preterm infants.

Focus on the potential role of this mixture in preterm infants was put by Westerbeek and coworkers in 5 following papers [69-73] .

As regards infectious morbidity [69] the authors reported that enteral supplementation of GOS/FOS/pAOS does not significantly reduce the risk of serious infectious morbidity in preterm infants even if they noticed a tendency toward a lower incidence of infections, especially for those caused by endogenous bacteria. The two papers of 2011 were centered on the effects on intestinal inflammation, as measured by fecal IL-8 and calprotectin [70] as well as on intestinal permeability of preterm infants [71]. Conclusions of both paper were not positive: the use of this mixture of prebiotics does not enhance the reduction of intestinal permeability in the first week of life [71] and the levels of fecal IL-8 and calprotectin are not positively affected.

A more recent paper on the use of this prebiotic mixture in preterm infants has been published by the same group [72]; this paper was aimed to investigate the fecal microbiota and intestinal microenvironment in preterm infants. In this case authors noticed an increase in the postnatal intestinal colonization, even if the extensive use of broad-spectrum antibiotics in preterm infants 
426 has a negative impact on of all component of the intestinal microbiota, then hampering and 427 delaying the normal microbiota development. In the same year the same group [73] tested 113 preterm infants to establish a potential link

429 between the use of these prebiotics and the vaccine antibody response. The selected vaccination was a diphtheria, tetanus, acellullar pertussis, polio and Haemophilus influenzae type b combination vaccine. The outcomes were negative as geometric mean titers were not different after prebiotic supplementation at 5 months of life and therefore authors' conclusions were that enteral supplementation of GOS/FOS/pAOS does not improve the immunization response in preterm infants.

These outcomes confirmed those reported two years before by Stam et al.[74] with a similar vaccine as they conclude that " no effect of prebiotics supplementation on vaccination specific antibody levels was found in children up to the age of 12 months; the vaccine specific antibody levels in infants fed the study prebiotics or a control diet were similar during the first year of life". atopic dermatitis in the first year of life. In this case healthy term infants with low atopy risk were recruited before the age of 8 weeks. A total of 414 infants were randomized to the prebiotic group, 416 infants to the control group (no prebiotics) and 300 infants were the reference breast-fed group. At the first birthday, atopic dermatitis occurred in significantly fewer infants from the prebiotic group than from the control group and the cumulative incidence of atopic dermatitis in the prebiotic group was in the low range of the breast-feeding group. Authors conclude that the number needed to prevent 1 case of atopic dermatitis by supplementation of prebiotics was 25 infants.

Opposite results were obtained by Boyle et al. [76] as regards eczema incidence. Infants with 449 a family history of allergic disease were randomized to be fed with an active $(n=432)$ or control (n $450=431$ ) formula until 6 months of age and the primary outcome was cumulative incidence of eczema 451 by 12 months. Eczema occurred by 12 months at $28.7 \%$ in both groups. Prebiotic formula did not 
452 change most immune markers but reduced cow's milk-specific IgG1 and increased regulatory T-cell 453 and plasmacytoid dendritic cell percentages.

454 Also a third paper published by Niele et al. [77] reported no effects when the 3 prebiotic 455 mixture is administered to potentially allergic infants. A short-term supplementation of 456 GOS/FOS/pAOS was administered during the first postnatal weeks. Incidence of allergic and 457 infectious diseases was assessed by validated questionnaires. The incidence of atopic dermatitis, 458 bronchial hyper-reactivity and infections of the upper and lower respiratory tract as well as 459 gastrointestinal diseases was not different between the groups. Infections occurrence in prebiotic treated groups was investigated by van Stuijvenberg et al.

461 [78] The objective of the study was to assess the number of fever episodes in the first year of life. 462 No effect of adding specific prebiotics to standard formula feeding was found in reducing the 463 number of fever episodes..

\section{Discussion}

In 2012 the European Society for Paediatric Gastroenterology Hepatology and Nutrition (ESPGHAN) underlined that the available scientific data suggest that formula supplemented with prebiotics and administered to healthy infants do not raise safety concerns with regard to growth and adverse effects.

The same evaluation has been recently presented by Skorka et al [11] as regards growth and tolerance parameters, so confirming the same statements of all most recent reviews [79-85]. Then the following considerations will be focused only on the efficacy of prebiotics as functionally active ingredients of infant formula.

\section{Effects on stool: consistency.}

Softer stool consistency is reported in substantially all papers that have checked this outcome, even in papers in which components more likely to have a bulking, fiber-like effects are absent $477[13,14,18,20,62]$. Quite significantly, for the evaluation of a dose-related effect, FOS seems to have 
478 effect on consistency when dosed at $0.3 \mathrm{~g} / 100 \mathrm{~mL}$ and not at a dose of $0.15 \mathrm{~g} / 100 \mathrm{~mL}$ [18] while

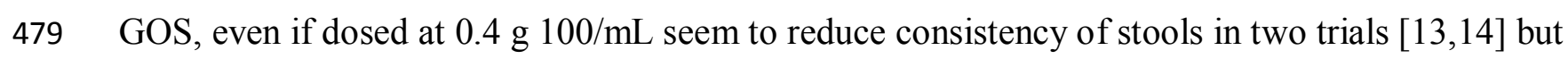
480 not in another [12].

However, a more significant difference about the incidence of hard stool has been reported when more than one prebiotic is used and at a higher dose: GOS/FOS are more active when dosed at $0.8 \mathrm{~g} / 100 \mathrm{~mL}$ when compared to $0.4 \mathrm{~g} / \mathrm{mL}[39,40,44]$.

The addition of pAOS to GOS/FOS does not seem to have an additional impact on stool consistency when compared to results for GOS/FOS [66]; the addition to PDX to GOS resulted in stool consistency very close to those reported for GOS/FOS $[59,62]$.

\section{Effects on stool: frequency.}

Reports on a positive impact on frequency are less frequent than the previous ones regarding consistency. Higher frequency were reported for FOS [18,20] GOS [14] GOS/FOS/pAOS [66] and in preterm $[55,56]$.

Gut -related effects: microbiota composition.

Substantially all papers reported some positive effects on the counts of bifidobacteria and lactobacilli, regardless of the kind of prebiotic, the daily dose and the length of treatment. The few pares reporting no increase in bifidobateria used a low dosage [43] or pAOS alone [66]. However, this general observation is in contrast with the reported outcomes "outside the gut" : as it will be showed below, outcomes related to immune system, allergy, infections are definitely more dose related. This could suggest that prebiotics have an impact on gut microbiota components different from those generally analyzed in all the published papers and that these still undetermined components of the intestinal bacterial ecosystems are the real responsible for the positive effects of prebiotics.

$\underline{\text { Gut }- \text { related effects: intestinal discomfort. }}$

Colic is one of the most common intestinal discomfort for infants; a potential role of the use of prebiotic substances in reducing colics has been reported by authors using GOS only at a low 
504 dosage [12] but also with GOS/FOS used in a fermented formula [54]. Reduction of excessive 505 crying was also reported by using PDX/GOS [64] or GOS/FOS at $0.8 \mathrm{~g} / 100 \mathrm{~mL}$ supplemented to a 506 fermented formula [54] but also with the simple addition of $0.4 \mathrm{~g} / 100 \mathrm{~mL}$ GOS [12]. Incidence of 507 diarrhea was reduced also when the $0.4 \mathrm{~g} / 100 \mathrm{~mL}$ dose was used [35].

Effects on the immune system and infections.

The effects on the immune systems seem those in which a marked effect of the dose could be observed.

Effects on the immune system and infections: allergy.

Improvements of the SCORAD evaluations have been reported for kestose [86] administered at $2 \mathrm{~g}$ /day but, quite interestingly for the scope of this paper, authors were unable to establish a link with the bifidobacteria counts. Quite interestingly, no changes in the incidence of allergy was noticed when $0.4 \mathrm{~g} / 100 \mathrm{~mL}$ were used [14] as well as $0.6 \mathrm{~g} / 100 \mathrm{~mL}$ [87]. Trials with GOS/FOS reported positive outcomes for atopy when the dose of $0.8 \mathrm{mg} / 100 \mathrm{~mL}$ was used [29] as well as for higher secretory immunoglobulin A levels [53], and serum immunoglobulin levels [30]. The addition of pAOS to GOS/FOS was reported to have no [74,77] or marginal effects [76].

\section{Effects on the immune system and infections: infections.}

The dose of $0.8 \mathrm{mg} / 100 \mathrm{~mL}$ has been shown to be active in reduction of all types of infections [33].

No effect on infections incidence for pAOS/GOS/FOS $[69,77,88]$. No effect on infections incidence for GOS/FOS dosed lower that $0.8 \mathrm{~g} / 100 \mathrm{~mL}$ [14].

Effects on preterm infants.

A number of papers reported the outcomes of prebiotic supplementation in preterm infants $[20,50-52,56-58,69-73,77,88]$. No problems of tolerance and safety were reported, regardless of the prebiotic mixture and dose used, even when a very high dose of GOS/FOS [56], higher than those used in full term infants $(0.4$ or $0.8 \mathrm{~g} 100 / \mathrm{mL})$ was aimed to evaluate tolerability and reduce stool viscosity and accelerate gastrointestinal transport, in order to improve feeding tolerance. Both 
these parameters were positively affected by the prebiotic supplementation in the 10 treated infants compared to the same number of control subjects.

As regards efficacy, there are conflicting reports about the use of prebiotic ingredients in this specific population group. Absence of results were reported by Modi et al. [57] when GOS/FOS at the usual dose of $0.8 \mathrm{~g} / 100 \mathrm{~mL}$ was fed to a large (79 subjects) cohort of preterm infants, with the aim to obtain a total milk intake of $150 \mathrm{~mL} / \mathrm{kg}$; on the contrary, the same prebiotic preparation [58] provided an increase of stool frequency, an improvement of feeding tolerance and reduction of bilirubin level; Indrio et al. [51,52] reported positive outcomes for gastric motility, results

confirmed by Dasopoulou et al. [50]. Absence of positive outcomes was also reported for the use of the pAOS/GOS/FOS mixture formulation in a series of papers by Westerbeek and coworkers [6971,88], by van den Berg et al. [73] and Niele et al. [77], with the exception of positive outcomes recorded for stool gut microbiota characteristics $[66,68,89]$..

\section{Conclusions}

In this paper we have tried to critically evaluate the outcomes, as reported by authors, of the use of prebiotic ingredients in feeding infants aged 0-12 months.

The overall appraisal on a potential dose effect on stool consistency and frequency is that a $0.3 \mathrm{~g} / 100 \mathrm{~mL}$ for fructans and $0.8 \mathrm{~g} / 100 \mathrm{~mL}$ for GOS/FOS seem to be the amount of choice in providing significant improvements of these two parameters, but lower doses and different composition of the prebiotic mixture have been shown to have positive effects. It could be possible, in a way similar to that describe for probiotics [10] to define these effects as "widespread".

More "rare" or "specific" are the effects on the immune system, allergy and the incidence of infections. The core information for this statement derives from the worth of papers dealing with the use of GOS/FOS at $0.8 \mathrm{~g} / 100 \mathrm{~mL}$, while the use of additionally components such as pAOS or PDX does not seem to have any significant effect.

Prebiotics in preterm infants seem to have little or no impact; however this could be due to a lack of a significant number of studies in large cohorts. 
From the microbial ecology point of view what could be concluded by the vast amount of data collected is that, while it is likely that any addition of prebiotic could induce some changes in the composition of the gut microbiota, a clinical significance could be achieved only with some specific prebiotic formulation and doses, and this specificity could be worthwhile to be addressed in the definition of the word "prebiotic".

Moreover, studies using the most updated techniques of Next Generation Sequencing, and the analysis of the microbiome composition and not of the microbiota only, are necessary to really understand the role of these ingredients in infant feeding.

The most recent studies [90-94] clearly supported the concept that gut microbiota of infants is more complex than a Bifidobacterium /Lactobacillus ecosystem. Evaluation of the impact of prebiotics on the strictly anaerobic population, such as Ruminococci, Lachnospiraceae, Blautia, could be the relevant target for new research and clinical trials.

\section{Supplementary Materials}

Table S1: List of all the references considered for the review.

Table S2: Human trials assessing the effects of a single prebiotic ingredient.

Table S3: The link between GOS/FOS administration and infant immune system.

Table S4: Effects of GOS/FOS with atypical dosages.

Table S5: Intestinal effects of GOS/FOS in term infants.

Table S6: Intestinal effects of GOS/FOS in preterm infants.

Table S6: Effects of polydextrose in association with other prebiotic ingredients.

Table S8: Trials assessing the effects of pectin hydrolysate-derived acidic oligosaccharides (pAOS) combined with GOS/FOS.

\section{Author Contributions}

M.L. developed the concept for the manuscript and wrote the first draft. V.P. and A.P. provided critical feedback and revised the text. All the authors approved the final version of the manuscript.

\section{Conflicts of Interest}


581 The authors declare no conflict of interest.

582

583

584

585

586

\section{References}

587

588

589

590

591

592

593

594

595

596

597

598

599

600

601

602

603

604

1. Gibson, G. R.; Roberfroid, M. B. Dietary modulation of the human colonic microbiota: introducing the concept of prebiotics. J. Nutr. 1995, 125, 1401-12, doi:10.1093/jn/125.6.1401.

2. Roberfroid, M. Prebiotics: the concept revisited. J. Nutr. 2007, 137, 830S-7S, doi:10.1093/jn/137.3.830S.

3. Reid, G.; Sanders, M. E.; Gaskins, H. R.; Gibson, G. R.; Mercenier, A.; Rastall, R.; Roberfroid, M.; Rowland, I.; Cherbut, C.; Klaenhammer, T. R. New scientific paradigms for probiotics and prebiotics. J. Clin. Gastroenterol. 2003, 37, 105-18.

4. Gibson, G. R.; Probert, H. M.; Loo, J. Van; Rastall, R. A.; Roberfroid, M. B. Dietary modulation of the human colonic microbiota: updating the concept of prebiotics. Nutr. Res. Rev. 2004, 17, 259-75, doi:10.1079/NRR200479.

5. Pineiro, M.; Asp, N.-G.; Reid, G.; Macfarlane, S.; Morelli, L.; Brunser, O.; Tuohy, K. FAO Technical Meeting on Prebiotics. J. Clin. Gastroenterol. 2008, 42, S156-S159, doi:10.1097/MCG.0b013e31817f184e.

6. Gibson, G. R.; Scott, K. P.; Rastall, R. A.; Tuohy, K. M.; Hotchkiss, A.; Dubert-Ferrandon, A.; Gareau, M.; Murphy, E. F.; Saulnier, D.; Loh, G.; Macfarlane, S.; Delzenne, N.; Ringel, Y.; Kozianowski, G.; Dickmann, R.; Lenoir-Wijnkoop, I.; Walker, C.; Buddington, R. Dietary prebiotics: current status and new definition. Food Sci. Technol. Bull. Funct. Foods 
605

606

607

608

609

610

611

612

613

614

615

616

617

618

619

620

621

622

623

624

625

626

627

2010, 7, 1-19, doi:10.1616/1476-2137.15880.

7. Bindels, L. B.; Delzenne, N. M.; Cani, P. D.; Walter, J. Towards a more comprehensive concept for prebiotics. Nat. Rev. Gastroenterol. Hepatol. 2015, 12, 303-10, doi:10.1038/nrgastro.2015.47.

8. Gibson, G. R.; Hutkins, R.; Sanders, M. E.; Prescott, S. L.; Reimer, R. A.; Salminen, S. J.; Scott, K.; Stanton, C.; Swanson, K. S.; Cani, P. D.; Verbeke, K.; Reid, G. Expert consensus document: The International Scientific Association for Probiotics and Prebiotics (ISAPP) consensus statement on the definition and scope of prebiotics. Nat. Rev. Gastroenterol. Hepatol. 2017, 14, 491-502, doi:10.1038/nrgastro.2017.75.

9. Fuller, R. Probiotics in man and animals. J. Appl. Bacteriol. 1989, 66, 365-78.

10. Hill, C.; Guarner, F.; Reid, G.; Gibson, G. R.; Merenstein, D. J.; Pot, B.; Morelli, L.; Canani, R. B.; Flint, H. J.; Salminen, S.; Calder, P. C.; Sanders, M. E. Expert consensus document. The International Scientific Association for Probiotics and Prebiotics consensus statement on the scope and appropriate use of the term probiotic. Nat. Rev. Gastroenterol. Hepatol. 2014, 11, 506-14, doi:10.1038/nrgastro.2014.66.

11. Skórka, A.; Pieścik-Lech, M.; Kołodziej, M.; Szajewska, H. Infant formulae supplemented with prebiotics: Are they better than unsupplemented formulae? An updated systematic review. Br. J. Nutr. 2018, 119, 810-825, doi:10.1017/S0007114518000120.

12. Giovannini, M.; Verduci, E.; Gregori, D.; Ballali, S.; Soldi, S.; Ghisleni, D.; Riva, E.; PLAGOS Trial Study Group Prebiotic effect of an infant formula supplemented with galactooligosaccharides: randomized multicenter trial. J. Am. Coll. Nutr. 2014, 33, 385-93, doi:10.1080/07315724.2013.878232.

13. Williams, T.; Choe, Y.; Price, P.; Katz, G.; Suarez, F.; Paule, C.; Mackey, A. Tolerance of 
628

629

630

631

632

633

634

635

636

637

638

639

640

641

642

643

644

645

646

647

648

649

650

651

formulas containing prebiotics in healthy, term infants. J. Pediatr. Gastroenterol. Nutr. 2014, 59, 653-8, doi:10.1097/MPG.0000000000000513.

14. Sierra, C.; Bernal, M.-J.; Blasco, J.; Martínez, R.; Dalmau, J.; Ortuño, I.; Espín, B.; Vasallo, M.-I.; Gil, D.; Vidal, M.-L.; Infante, D.; Leis, R.; Maldonado, J.; Moreno, J.-M.; Román, E. Prebiotic effect during the first year of life in healthy infants fed formula containing GOS as the only prebiotic: a multicentre, randomised, double-blind and placebo-controlled trial. Eur. J. Nutr. 2015, 54, 89-99, doi:10.1007/s00394-014-0689-9.

15. Boženský, J.; Hill, M.; Zelenka, R.; Skýba, T. Prebiotics do not influence the severity of atopic dermatitis in infants: A randomised controlled trial. PLoS One 2015, 10, 1-8, doi:10.1371/journal.pone.0142897.

16. Paganini, D.; Uyoga, M. A.; Kortman, G. A. M.; Cercamondi, C. I.; Moretti, D.; BarthJaeggi, T.; Schwab, C.; Boekhorst, J.; Timmerman, H. M.; Lacroix, C.; Karanja, S.; Zimmermann, M. B. Prebiotic galacto-oligosaccharides mitigate the adverse effects of iron fortification on the gut microbiome: a randomised controlled study in Kenyan infants. Gut 2017, 66, 1956-1967, doi:10.1136/gutjnl-2017-314418.

17. Underwood, M. A.; Kalanetra, K. M.; Bokulich, N. A.; Mirmiran, M.; Barile, D.; Tancredi, D. J.; German, J. B.; Lebrilla, C. B.; Mills, D. A. Prebiotic oligosaccharides in premature infants. J. Pediatr. Gastroenterol. Nutr. 2014, 58, 352-60, doi:10.1097/MPG.0000000000000211.

18. Euler, A. R.; Mitchell, D. K.; Kline, R.; Pickering, L. K. Prebiotic effect of fructooligosaccharide supplemented term infant formula at two concentrations compared with unsupplemented formula and human milk. J. Pediatr. Gastroenterol. Nutr. 2005, 40, 157-64.

19. Brunser, O.; Figueroa, G.; Gotteland, M.; Haschke-Becher, E.; Magliola, C.; Rochat, F.; Cruchet, S.; Palframan, R.; Gibson, G.; Chauffard, F.; Haschke, F. Effects of probiotic or 


\begin{abstract}
652 prebiotic supplemented milk formulas on fecal microbiota composition of infants. Asia Pac. 653 J. Clin. Nutr. 2006, 15, 368-376.
\end{abstract}

654 20. Kapiki, A.; Costalos, C.; Oikonomidou, C.; Triantafyllidou, A.; Loukatou, E.; Pertrohilou, V. 655 The effect of a fructo-oligosaccharide supplemented formula on gut flora of preterm infants. 656 Early Hum. Dev. 2007, 83, 335-9, doi:10.1016/j.earlhumdev.2006.07.003.

657 21. Khoshoo, V.; Sun, S. S.; Storm, H. Tolerance of an enteral formula with insoluble and 658 prebiotic fiber in children with compromised gastrointestinal function. J. Am. Diet. Assoc. $659 \quad 2010,110,1728-1733$, doi:10.1016/j.jada.2010.08.011.

660 22. Xia, Q.; Williams, T.; Hustead, D.; Price, P.; Morrison, M.; Yu, Z. Quantitative analysis of 661 intestinal bacterial populations from term infants fed formula supplemented with fructo662 oligosaccharides. J. Pediatr. Gastroenterol. Nutr. 2012, 55, 314-320, 663 doi:10.1097/MPG.0b013e3182523254.

664 665 666 667 668 669 670 671 672 673 674 675

23. Shibata, R.; Kimura, M.; Takahashi, H.; Mikami, K.; Aiba, Y.; Takeda, H.; Koga, Y. Clinical effects of kestose, a prebiotic oligosaccharide, on the treatment of atopic dermatitis in infants. Clin. Exp. Allergy 2009, 39, 1397-1403, doi:10.1111/j.1365-2222.2009.03295.x.

24. López-Velázquez, G.; Díaz-García, L.; Anzo, A.; Parra-Ortiz, M.; Llamosas-Gallardo, B.; Ortiz-Hernández, A. A.; Mancilla-Ramírez, J.; Cruz-Rubio, J. M.; Gutiérrez-Castrellón, P. Safety of a dual potential prebiotic system from Mexican agave "Metlin ${ }^{\circledR}$ and Metlos®", incorporated to an infant formula for term newborn babies: a randomized controlled trial. Rev. Invest. Clin. 65, 483-90.

25. López-Velázquez, G.; Parra-Ortiz, M.; Mora, I. D. la M.-D. la; García-Torres, I.; EnríquezFlores, S.; Alcántara-Ortigoza, M. A.; Angel, A. G.-D.; Velázquez-Aragón, J.; OrtizHernández, R.; Cruz-Rubio, J. M.; Villa-Barragán, P.; Jiménez-Gutiérrez, C.; GutiérrezCastrellón, P. Effects of Fructans from Mexican Agave in Newborns Fed with Infant 
Formula: A Randomized Controlled Trial. Nutrients 2015, 7, 8939-51, doi:10.3390/nu7115442.

26. Kim, S. H.; Da, H. L.; Meyer, D. Supplementation of infant formula with native inulin has a prebiotic effect in formula-fed babies. Asia Pac. J. Clin. Nutr. 2007, 16, 172-177.

27. Closa-Monasterolo, R.; Gispert-Llaurado, M.; Luque, V.; Ferre, N.; Rubio-Torrents, C.; Zaragoza-Jordana, M.; Escribano, J. Safety and efficacy of inulin and oligofructose supplementation in infant formula: Results from a randomized clinical trial. Clin. Nutr. 2013, 32, 918-927, doi:10.1016/j.clnu.2013.02.009.

28. Nowacki, J.; Lee, H.-C.; Lien, R.; Cheng, S.-W.; Li, S.-T.; Yao, M.; Northington, R.; Jan, I.; Mutungi, G. Stool fatty acid soaps, stool consistency and gastrointestinal tolerance in term infants fed infant formulas containing high sn-2 palmitate with or without oligofructose: a double-blind, randomized clinical trial. Nutr. J. 2014, 13, 105, doi:10.1186/1475-2891-13105.

29. Moro, G.; Arslanoglu, S.; Stahl, B.; Jelinek, J.; Wahn, U.; Boehm, G. A mixture of prebiotic oligosaccharides reduces the incidence of atopic dermatitis during the first six months of age. Arch. Dis. Child. 2006, 91, 814-9, doi:10.1136/adc.2006.098251.

30. van Hoffen, E.; Ruiter, B.; Faber, J.; M’Rabet, L.; Knol, E. F.; Stahl, B.; Arslanoglu, S.; Moro, G.; Boehm, G.; Garssen, J. A specific mixture of short-chain galacto-oligosaccharides and long-chain fructo-oligosaccharides induces a beneficial immunoglobulin profile in infants at high risk for allergy. Allergy 2009, 64, 484-7, doi:10.1111/j.13989995.2008.01765.x.

31. Schouten, B.; Van Esch, B. C. A. M.; Kormelink, T. G.; Moro, G. E.; Arslanoglu, S.; Boehm, G.; Knippels, L. M. J.; Redegeld, F. A.; Willemsen, L. E. M.; Garssen, J. Non-digestible oligosaccharides reduce immunoglobulin free light-chain concentrations in infants at risk for 
allergy. Pediatr. Allergy Immunol. 2011, 22, 537-42, doi:10.1111/j.1399-3038.2010.01132.x.

32. MacDonald, A.; Cochrane, B.; Wopereis, H.; Loveridge, N. Specific prebiotics in a formula for infants with Phenylketonuria. Mol. Genet. Metab. 2011, 104 Suppl, S55-9, doi:10.1016/j.ymgme.2011.09.015.

33. Arslanoglu, S.; Moro, G. E.; Boehm, G. Early supplementation of prebiotic oligosaccharides protects formula-fed infants against infections during the first 6 months of life. J. Nutr. 2007, 137, 2420-4, doi:10.1093/jn/137.11.2420.

34. Bisceglia, M.; Indrio, F.; Riezzo, G.; Poerio, V.; Corapi, U.; Raimondi, F. The effect of prebiotics in the management of neonatal hyperbilirubinaemia. Acta Paediatr. 2009, 98, 1579-81, doi:10.1111/j.1651-2227.2009.01387.x.

35. Bruzzese, E.; Volpicelli, M.; Squeglia, V.; Bruzzese, D.; Salvini, F.; Bisceglia, M.; Lionetti, P.; Cinquetti, M.; Iacono, G.; Amarri, S.; Guarino, A. A formula containing galacto- and fructo-oligosaccharides prevents intestinal and extra-intestinal infections: an observational study. Clin. Nutr. 2009, 28, 156-61, doi:10.1016/j.clnu.2009.01.008.

36. Brunser, O.; Gotteland, M.; Cruchet, S.; Figueroa, G.; Garrido, D.; Steenhout, P. Effect of a milk formula with prebiotics on the intestinal microbiota of infants after an antibiotic treatment. Pediatr. Res. 2006, 59, 451-6, doi:10.1203/01.pdr.0000198773.40937.61.

37. Alliet, P.; Scholtens, P.; Raes, M.; Hensen, K.; Jongen, H.; Rummens, J.-L.; Boehm, G.; Vandenplas, Y. Effect of prebiotic galacto-oligosaccharide, long-chain fructooligosaccharide infant formula on serum cholesterol and triacylglycerol levels. Nutrition 2007, 23, 719-23, doi:10.1016/j.nut.2007.06.011.

38. Moro, G.; Minoli, I.; Mosca, M.; Fanaro, S.; Jelinek, J.; Stahl, B.; Boehm, G. Dosage-related bifidogenic effects of galacto- and fructooligosaccharides in formula-fed term infants. $J$. 
Pediatr. Gastroenterol. Nutr. 2002, 34, 291-5.

39. Moro, G. E.; Mosca, F.; Miniello, V.; Fanaro, S.; Jelinek, J.; Stahl, B.; Boehm, G. Effects of a new mixture of prebiotics on faecal flora and stools in term infants. Acta Paediatr. Suppl. 2003, 91, 77-9.

40. Knol, J.; Scholtens, P.; Kafka, C.; Steenbakkers, J.; Gro, S.; Helm, K.; Klarczyk, M.; Schöpfer, H.; Böckler, H.-M.; Wells, J. Colon microflora in infants fed formula with galactoand fructo-oligosaccharides: more like breast-fed infants. J. Pediatr. Gastroenterol. Nutr. 2005, 40, 36-42.

41. Haarman, M.; Knol, J. Quantitative real-time PCR assays to identify and quantify fecal Bifidobacterium species in infants receiving a prebiotic infant formula. Appl. Environ. Microbiol. 2005, 71, 2318-24, doi:10.1128/AEM.71.5.2318-2324.2005.

42. Haarman, M.; Knol, J. Quantitative real-time PCR analysis of fecal Lactobacillus species in infants receiving a prebiotic infant formula. Appl. Environ. Microbiol. 2006, 72, 2359-65, doi:10.1128/AEM.72.4.2359-2365.2006.

43. Bakker-Zierikzee, A. M.; Alles, M. S.; Knol, J.; Kok, F. J.; Tolboom, J. J. M.; Bindels, J. G. Effects of infant formula containing a mixture of galacto- and fructo-oligosaccharides or viable Bifidobacterium animalis on the intestinal microflora during the first 4 months of life. Br. J. Nutr. 2005, 94, 783-90.

44. Costalos, C.; Kapiki, A.; Apostolou, M.; Papathoma, E. The effect of a prebiotic supplemented formula on growth and stool microbiology of term infants. Early Hum. Dev. 2008, 84, 45-9, doi:10.1016/j.earlhumdev.2007.03.001.

45. Holscher, H. D.; Faust, K. L.; Czerkies, L. A.; Litov, R.; Ziegler, E. E.; Lessin, H.; Hatch, T.; Sun, S.; Tappenden, K. A. Effects of prebiotic-containing infant formula on gastrointestinal 

tolerance and fecal microbiota in a randomized controlled trial. JPEN. J. Parenter. Enteral Nutr. 2012, 36, 95S-105S, doi:10.1177/0148607111430087.

46. Vivatvakin, B.; Mahayosnond, A.; Theamboonlers, A.; Steenhout, P. G.; Conus, N. J. Effect of a whey-predominant starter formula containing LCPUFAs and oligosaccharides (FOS/GOS) on gastrointestinal comfort in infants. Asia Pac. J. Clin. Nutr. 2010, 19, 473-80.

47. Veereman-Wauters, G.; Staelens, S.; Van de Broek, H.; Plaskie, K.; Wesling, F.; Roger, L. C.; McCartney, A. L.; Assam, P. Physiological and bifidogenic effects of prebiotic supplements in infant formulae. J. Pediatr. Gastroenterol. Nutr. 2011, 52, 763-71, doi:10.1097/MPG.0b013e3182139f39.

48. Salvini, F.; Riva, E.; Salvatici, E.; Boehm, G.; Jelinek, J.; Banderali, G.; Giovannini, M. A specific prebiotic mixture added to starting infant formula has long-lasting bifidogenic effects. J. Nutr. 2011, 141, 1335-9, doi:10.3945/jn.110.136747.

49. Szajewska, H.; Ruszczyński, M.; Szymański, H.; Sadowska-Krawczenko, I.; Piwowarczyk, A.; Rasmussen, P. B.; Kristensen, M. B.; West, C. E.; Hernell, O. Effects of infant formula supplemented with prebiotics compared with synbiotics on growth up to the age of $12 \mathrm{mo}$ : a randomized controlled trial. Pediatr. Res. 2017, 81, 752-758, doi:10.1038/pr.2017.5.

50. Dasopoulou, M.; Briana, D. D.; Boutsikou, T.; Karakasidou, E.; Roma, E.; Costalos, C.; Malamitsi-Puchner, A. Motilin and gastrin secretion and lipid profile in preterm neonates following prebiotics supplementation: a double-blind randomized controlled study. JPEN. J. Parenter. Enteral Nutr. 2015, 39, 359-68, doi:10.1177/0148607113510182.

51. Indrio, F.; Riezzo, G.; Raimondi, F.; Bisceglia, M.; Cavallo, L.; Francavilla, R. Effects of probiotic and prebiotic on gastrointestinal motility in newborns. J. Physiol. Pharmacol. 2009, 60, 27-31, doi:10.1016/j.iccn.2010.07.001. 


\begin{abstract}
769 52. Indrio, F.; Riezzo, G.; Raimondi, F.; Francavilla, R.; Montagna, O.; Valenzano, M. L.; 770 Cavallo, L.; Boehm, G. Prebiotics improve gastric motility and gastric electrical activity in 771 preterm newborns. J. Pediatr. Gastroenterol. Nutr. 2009, 49, 258-61, doi:10.1097/MPG.0b013e3181926aec.
\end{abstract}

773

53. Huet, F.; Abrahamse-Berkeveld, M.; Tims, S.; Simeoni, U.; Beley, G.; Savagner, C.; Vandenplas, Y.; Hourihane, J. O. Partly Fermented Infant Formulae With Specific Oligosaccharides Support Adequate Infant Growth and Are Well-Tolerated. J. Pediatr. Gastroenterol. Nutr. 2016, 63, e43-53, doi:10.1097/MPG.0000000000001360.

54. Vandenplas, Y.; Ludwig, T.; Bouritius, H.; Alliet, P.; Forde, D.; Peeters, S.; Huet, F.; Hourihane, J. Randomised controlled trial demonstrates that fermented infant formula with short-chain galacto-oligosaccharides and long-chain fructo-oligosaccharides reduces the incidence of infantile colic. Acta Paediatr. 2017, 106, 1150-1158, doi:10.1111/apa.13844.

55. Boehm, G.; Lidestri, M.; Casetta, P.; Jelinek, J.; Negretti, F.; Stahl, B.; Marini, A. Supplementation of a bovine milk formula with an oligosaccharide mixture increases counts of faecal bifidobacteria in preterm infants. Arch. Dis. Child. Fetal Neonatal Ed. 2002, 86, F178-81.

56. Mihatsch, W. A.; Hoegel, J.; Pohlandt, F. Prebiotic oligosaccharides reduce stool viscosity and accelerate gastrointestinal transport in preterm infants. Acta Paediatr. 2006, 95, 843-8, doi:10.1080/08035250500486652.

57. Modi, N.; Uthaya, S.; Fell, J.; Kulinskaya, E. A randomized, double-blind, controlled trial of the effect of prebiotic oligosaccharides on enteral tolerance in preterm infants (ISRCTN77444690). Pediatr. Res. 2010, 68, 440-5, doi:10.1203/PDR.0b013e3181flcd59.

58. Armanian, A. M.; Barekatain, B.; Hoseinzadeh, M.; Salehimehr, N. Prebiotics for the management of hyperbilirubinemia in preterm neonates. J. Matern. Fetal. Neonatal Med. 
793

794

795

796

797

798

799

800

801

802

803

804

805

806

807

808

809

810

811

812

813

814

815

816

2016, 29, 3009-13, doi:10.3109/14767058.2015.1113520.

59. Ziegler, E.; Vanderhoof, J. A.; Petschow, B.; Mitmesser, S. H.; Stolz, S. I.; Harris, C. L.; Berseth, C. L. Term infants fed formula supplemented with selected blends of prebiotics grow normally and have soft stools similar to those reported for breast-fed infants. J. Pediatr. Gastroenterol. Nutr. 2007, 44, 359-64, doi:10.1097/MPG.0b013e31802fca8c.

60. Nakamura, N.; Gaskins, H. R.; Collier, C. T.; Nava, G. M.; Rai, D.; Petschow, B.; Russell, W. M.; Harris, C.; Mackie, R. I.; Wampler, J. L.; Walker, D. C. Molecular ecological analysis of fecal bacterial populations from term infants fed formula supplemented with selected blends of prebiotics. Appl. Environ. Microbiol. 2009, 75, 1121-8, doi:10.1128/AEM.02359-07.

61. Scalabrin, D. M. F.; Mitmesser, S. H.; Welling, G. W.; Harris, C. L.; Marunycz, J. D.; Walker, D. C.; Bos, N. A.; Tölkkö, S.; Salminen, S.; Vanderhoof, J. A. New prebiotic blend of polydextrose and galacto-oligosaccharides has a bifidogenic effect in young infants. $J$. Pediatr. Gastroenterol. Nutr. 2012, 54, 343-52, doi:10.1097/MPG.0b013e318237ed95.

62. Ashley, C.; Johnston, W. H.; Harris, C. L.; Stolz, S. I.; Wampler, J. L.; Berseth, C. L. Growth and tolerance of infants fed formula supplemented with polydextrose (PDX) and/or galactooligosaccharides (GOS): double-blind, randomized, controlled trial. Nutr. J. 2012, 11, 38, doi:10.1186/1475-2891-11-38.

63. Hicks, P. D.; Hawthorne, K. M.; Berseth, C. L.; Marunycz, J. D.; Heubi, J. E.; Abrams, S. A. Total calcium absorption is similar from infant formulas with and without prebiotics and exceeds that in human milk-fed infants. BMC Pediatr. 2012, 12, 118, doi:10.1186/14712431-12-118.

64. Pärtty, A.; Luoto, R.; Kalliomäki, M.; Salminen, S.; Isolauri, E. Effects of early prebiotic and probiotic supplementation on development of gut microbiota and fussing and crying in 
preterm infants: a randomized, double-blind, placebo-controlled trial. J. Pediatr. 2013, 163, 1272-7.e1-2, doi:10.1016/j.jpeds.2013.05.035.

65. Luoto, R.; Ruuskanen, O.; Waris, M.; Kalliomäki, M.; Salminen, S.; Isolauri, E. Prebiotic and probiotic supplementation prevents rhinovirus infections in preterm infants: a randomized, placebo-controlled trial. J. Allergy Clin. Immunol. 2014, 133, 405-13, doi:10.1016/j.jaci.2013.08.020.

66. Fanaro, S.; Jelinek, J.; Stahl, B.; Boehm, G.; Kock, R.; Vigi, V. Acidic Oligosaccharides from Pectin Hydrolysate as New Component for Infant Formulae: Effect on Intestinal Flora, Stool Characteristics, and pH. J. Pediatr. Gastroenterol. Nutr. 2005, 41, 186-190, doi:10.1097/01.mpg.0000172747.64103.d7.

67. Magne, F.; Hachelaf, W.; Suau, A.; Boudraa, G.; Bouziane-Nedjadi, K.; Rigottier-Gois, L.; Touhami, M.; Desjeux, J.-F.; Pochart, P. Effects on faecal microbiota of dietary and acidic oligosaccharides in children during partial formula feeding. J. Pediatr. Gastroenterol. Nutr. 2008, 46, 580-8, doi:10.1097/MPG.0b013e318164d920.

68. Piemontese, P.; Giannì, M. L.; Braegger, C. P.; Chirico, G.; Grüber, C.; Riedler, J.; Arslanoglu, S.; van Stuijvenberg, M.; Boehm, G.; Jelinek, J.; Roggero, P.; MIPS 1 Working Group Tolerance and safety evaluation in a large cohort of healthy infants fed an innovative prebiotic formula: a randomized controlled trial. PLoS One 2011, 6, e28010, doi:10.1371/journal.pone.0028010.

69. Westerbeek, E. A.; van den Berg, J. P.; Lafeber, H. N.; Fetter, W. P.; Boehm, G.; Twisk, J. W.; van Elburg, R. M. Neutral and acidic oligosaccharides in preterm infants: a randomized, double-blind, placebo-controlled trial. Am. J. Clin. Nutr. 2010, 91, 679-86, doi:10.3945/ajen.2009.28625. 


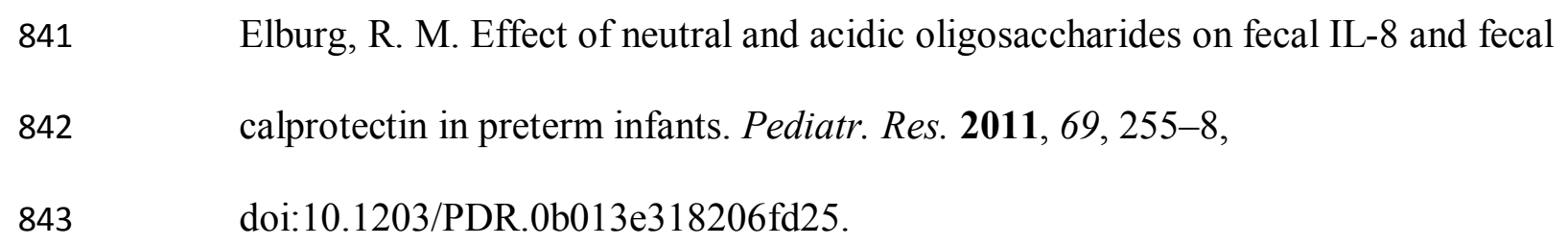

72. Westerbeek, E. A. M.; Slump, R. A.; Lafeber, H. N.; Knol, J.; Georgi, G.; Fetter, W. P. F.;

73. van den Berg, J. P.; Westerbeek, E. A. M.; van der Klis, F. R. M.; Berbers, G. A. M.;

74. Stam, J.; van Stuijvenberg, M.; Garssen, J.; Knipping, K.; Sauer, P. J. J. A mixture of three prebiotics does not affect vaccine specific antibody responses in healthy term infants in the first year of life. Vaccine 2011, 29, 7766-72, doi:10.1016/j.vaccine.2011.07.110.

76. Boyle, R. J.; Tang, M. L.-K.; Chiang, W. C.; Chua, M. C.; Ismail, I.; Nauta, A.; Hourihane, J. 
865

866

867

868 869

870

871

872

873

874

875

876

877

878

879

880

881

882

883

884

885

886

887

A.; Garssen, J.; Warner, J. O.; PATCH study investigators Prebiotic-supplemented partially hydrolysed cow's milk formula for the prevention of eczema in high-risk infants: a randomized controlled trial. Allergy 2016, 71, 701-10, doi:10.1111/all.12848.

77. Niele, N.; van Zwol, A.; Westerbeek, E. A. M.; Lafeber, H. N.; van Elburg, R. M. Effect of non-human neutral and acidic oligosaccharides on allergic and infectious diseases in preterm infants. Eur. J. Pediatr. 2013, 172, 317-23, doi:10.1007/s00431-012-1886-2.

78. van Stuijvenberg, M.; Eisses, A. M.; Grüber, C.; Mosca, F.; Arslanoglu, S.; Chirico, G.; Braegger, C. P.; Riedler, J.; Boehm, G.; Sauer, P. J. J. Do prebiotics reduce the number of fever episodes in healthy children in their first year of life: a randomised controlled trial. $B r$. J. Nutr. 2011, 106, 1740-8, doi:10.1017/S0007114511004053.

79. Rao, S.; Srinivasjois, R.; Patole, S. Prebiotic supplementation in full-term neonates: a systematic review of randomized controlled trials. Arch. Pediatr. Adolesc. Med. 2009, 163, 755-64, doi:10.1001/archpediatrics.2009.94.

80. Mugambi, M. N.; Musekiwa, A.; Lombard, M.; Young, T.; Blaauw, R. Synbiotics, probiotics or prebiotics in infant formula for full term infants: a systematic review. Nutr. J. 2012, 11, 81, doi:10.1186/1475-2891-11-81.

81. Osborn, D. A.; Sinn, J. K. H. Prebiotics in infants for prevention of allergy. Cochrane database Syst. Rev. 2013, CD006474, doi:10.1002/14651858.CD006474.pub3.

82. Vandenplas, Y.; De Greef, E.; Veereman, G. Prebiotics in infant formula. Gut Microbes 2014, 5, 681-7, doi:10.4161/19490976.2014.972237.

83. Cuello-Garcia, C.; Fiocchi, A.; Pawankar, R.; Yepes-Nuñez, J. J.; Morgano, G. P.; Zhang, Y.; Agarwal, A.; Gandhi, S.; Terracciano, L.; Schünemann, H. J.; Brozek, J. L. Prebiotics for the prevention of allergies: A systematic review and meta-analysis of randomized controlled 
888

889

890

891

892

893

894

895

896

897

898

899

900

901

902

903

904

905

906

907

908

909

910

trials. Clin. Exp. Allergy 2017, 47, 1468-1477, doi:10.1111/cea.13042.

84. La Fata, G.; Rastall, R. A.; Lacroix, C.; Harmsen, H. J. M.; Mohajeri, M. H.; Weber, P.;

Steinert, R. E. Recent Development of Prebiotic Research-Statement from an Expert Workshop. Nutrients 2017, 9, doi:10.3390/nu9121376.

85. Lei, W.-T.; Shih, P.-C.; Liu, S.-J.; Lin, C.-Y.; Yeh, T.-L. Effect of Probiotics and Prebiotics on Immune Response to Influenza Vaccination in Adults: A Systematic Review and MetaAnalysis of Randomized Controlled Trials. Nutrients 2017, 9, 1175, doi:10.3390/nu9111175.

86. Shibata, R.; Kimura, M.; Takahashi, H.; Mikami, K.; Aiba, Y.; Takeda, H.; Koga, Y. Clinical effects of kestose, a prebiotic oligosaccharide, on the treatment of atopic dermatitis in infants. Clin. Exp. Allergy 2009, 39, 1397-403, doi:10.1111/j.1365-2222.2009.03295.x.

87. Raes, M.; Scholtens, P. A. M. J.; Alliet, P.; Hensen, K.; Jongen, H.; Boehm, G.; Vandenplas, Y.; Rummens, J. L. Exploration of basal immune parameters in healthy infants receiving an infant milk formula supplemented with prebiotics. Pediatr. Allergy Immunol. 2010, 21, e37785, doi:10.1111/j.1399-3038.2009.00957.x.

88. Westerbeek, E. A. M.; van Elburg, R. M.; van den Berg, A.; van den Berg, J.; Twisk, J. W. R.; Fetter, W. P. F.; Lafeber, H. N. Design of a randomised controlled trial on immune effects of acidic and neutral oligosaccharides in the nutrition of preterm infants: carrot study. BMC Pediatr. 2008, 8, 46, doi:10.1186/1471-2431-8-46.

89. Westerbeek, E. A. M.; Hensgens, R. L.; Mihatsch, W. A.; Boehm, G.; Lafeber, H. N.; van Elburg, R. M. The effect of neutral and acidic oligosaccharides on stool viscosity, stool frequency and stool $\mathrm{pH}$ in preterm infants. Acta Paediatr. 2011, 100, 1426-31, doi:10.1111/j.1651-2227.2011.02295.x.

90. Sagheddu, V.; Patrone, V.; Miragoli, F.; Puglisi, E.; Morelli, L. Infant Early Gut 
Colonization by Lachnospiraceae: High Frequency of Ruminococcus gnavus. Front. Pediatr. 2016, 4, 57, doi:10.3389/fped.2016.00057.

91. Sagheddu, V.; Patrone, V.; Miragoli, F.; Morelli, L. Abundance and Diversity of Hydrogenotrophic Microorganisms in the Infant Gut before the Weaning Period Assessed by Denaturing Gradient Gel Electrophoresis and Quantitative PCR. Front. Nutr. 2017, 4, 29, doi:10.3389/fnut.2017.00029.

92. Piacentini, G.; Peroni, D.; Bessi, E.; Morelli, L. Molecular characterization of intestinal microbiota in infants fed with soymilk. J. Pediatr. Gastroenterol. Nutr. 2010, 51, 71-6, doi:10.1097/MPG.0b013e3181dc8b02.

93. Timmerman, H. M.; Rutten, N. B. M. M.; Boekhorst, J.; Saulnier, D. M.; Kortman, G. A. M.; Contractor, N.; Kullen, M.; Floris, E.; Harmsen, H. J. M.; Vlieger, A. M.; Kleerebezem, M.; Rijkers, G. T. Intestinal colonisation patterns in breastfed and formula-fed infants during the first 12 weeks of life reveal sequential microbiota signatures. Sci. Rep. 2017, 7, 8327, doi:10.1038/s41598-017-08268-4.

94. Chang, J. Y.; Shin, S. M.; Chun, J.; Lee, J.-H.; Seo, J.-K. Pyrosequencing-based molecular monitoring of the intestinal bacterial colonization in preterm infants. J. Pediatr.

Gastroenterol. Nutr. 2011, 53, 512-9, doi:10.1097/MPG.0b013e318227e518. 